\title{
Altered oscillatory brain dynamics of emotional processing in young binge drinkers
}

\author{
Siyuan Huang ${ }^{1}$ - Lee A. Holcomb ${ }^{1}$. Stephen M. Cruz ${ }^{2}$ Ksenija Marinkovic ${ }^{1,3}$
}

Published online: 10 November 2017

(C) Psychonomic Society, Inc. 2017

\begin{abstract}
Heavy episodic drinking, also termed binge drinking, is commonly practiced by young adults. It is accompanied by a range of cognitive, affective, and social problems, but the neural dynamics underlying changes in emotional functions is poorly understood. To investigate the behavioral and brain indices of affective processing as a function of binge drinking, young, healthy participants ( $23.3 \pm 3.3$ years) were assigned to two groups ( $n=32$ each) based on their drinking habits. Binge drinking (BD) participants reported drinking heavily with at least five binge episodes in the last 6 months, whereas light drinkers (LD) reported no more than one binge episode in the last 6 months. Participants provided subjective ratings of emotionally evocative images with negative, positive, erotic, and neutral themes mostly selected from the International Affective Picture System (IAPS). Electroencephalography (EEG) signal was recorded with a 64-channel system and analyzed in theta frequency band $(4-7 \mathrm{~Hz})$ with Morlet wavelets. Subjective ratings of the IAPS pictures were equivalent across both groups. However, affective modulation of eventrelated theta power both during early appraisal and later integrative processing stages was attenuated in $\mathrm{BD}$, particularly those engaging in high-intensity drinking. These findings suggest that binge drinking is associated with altered
\end{abstract}

Ksenija Marinkovic

kmarinkovic@mail.sdsu.edu

1 Department of Psychology, San Diego State University, San Diego, CA, USA

2 Department of Biology, San Diego State University, San Diego, CA, USA

3 Department of Radiology, University of California, San Diego, CA, USA neurophysiological indices of affective functions that are reflected in lower theta responsivity to emotions. The blunted long-range cortico-cortical and corticolimbic integration is consistent with compromised affective functions in alcohol use disorder. These findings may have implications for diagnostic and intervention strategies in heavy alcohol users.

Keywords Binge drinking $\cdot$ Emotional processing $\cdot$ EEG . Theta oscillations · International Affective Picture System

Drinking is an essential aspect of social situations across many cultures. It is commonly associated with positive expected outcomes in affective and social domains including enhancement of mood and pleasure, greater ease of social interactions, and reduction of anxiety (Jones, Corbin, \& Fromme, 2001) These expectancies are partly borne out by reports of improved positive feelings (Dolder et al., 2017) and diminished anxiety responses to social stressors during alcohol intoxication (Sayette, Smith, Breiner, \& Wilson, 1992; Sher, Bartholow, Peuser, Erickson, \& Wood, 2007). However, studies indicate that alcohol intoxication impairs affective functions, including recognition of emotional facial expressions (Attwood \& Munafo, 2014; Borrill, Rosen, \& Summerfield, 1987), emotional pictures (Knowles \& Duka, 2004), and the ability to control aggression (Pihl \& Sutton, 2009). Electroencephalography (EEG) measures of emotional processing are also altered by acute alcohol challenge. In an emotional go/no-go task, faces with emotional expression evoked larger N200 and smaller P300 amplitudes during moderate intoxication (Euser \& Franken, 2012). Late event-related potentials (ERPs) were similarly reduced to unpleasant pictures during alcohol challenge (Franken, Nijs, Muris, \& Van Strien, 2007). These results lend support to the dampening effects of 
acute alcohol intoxication on the behavioral and brain responses to emotionally valenced stimuli.

Studies in individuals with alcohol use disorder (AUD) provide extensive evidence that long-term alcohol abuse is associated with a wide range of emotional impairments (D'Hondt, Campanella, Kornreich, Philippot, \& Maurage, 2014; Oscar-Berman \& Marinkovic, 2007). The most common emotional alterations include deficits in emotional differentiation of facial expressions (Kornreich et al., 2013; Kornreich et al., 2002; Maurage, Campanella, Philippot, de Timary, et al., 2008; Philippot et al., 1999), voices (Maurage, Campanella, et al., 2009; Monnot, Lovallo, Nixon, \& Ross, 2002), body postures (Maurage, Campanella, et al., 2009), and contextual scenes (Grynberg, Maurage, \& Nandrino, 2017). Neuroimaging studies have revealed alcoholismrelated functional and structural perturbations in corticolimbic and frontoparietal circuits that are pivotal for emotional and social functioning (Makris et al., 2008; Marinkovic et al., 2009; Muller-Oehring \& Schulte, 2014; Oscar-Berman et al., 2014; Sullivan \& Pfefferbaum, 2005). Studies using ERPs have reported reduced neural activity associated with early visuospatial perception and subsequent cognitive elaboration of emotional facial expressions in individuals with AUD (Maurage, Campanella, Philippot, de Timary, et al., 2008; Maurage, Campanella, Philippot, Vermeulen, et al., 2008; Maurage et al., 2007). Furthermore, lower levels of skin conductance reactivity were reported in abstinent alcoholics in response to faces (Sawyer, Poey, Ruiz, Marinkovic, \& Oscar-Berman, 2015). Taken together, emotional deficiencies reported in alcoholic individuals are multifaceted, encompass different neurofunctional systems, and are associated with interpersonal difficulties observed in this population (Kornreich et al., 2002).

Even though heavy episodic drinking, also known as binge drinking, is a serious public health problem, its possible association with emotional deficits has not been well studied. Binge drinking is commonly defined as imbibing at least five drinks for men and four drinks for women in about 2 hours, which may raise the blood alcohol concentration to $0.08 \%$ (National Institute on Alcohol Abuse and Alcoholism, 2017). This drinking pattern is common among young adults, and it represents a large problem on college campuses (Wechsler et al., 2002). Binge drinking is accompanied by a broad spectrum of mental health problems such as depression, anxiety, stress, and interpersonal difficulties (Kuntsche, Rehm, \& Gmel, 2004; Laukkanen, Shemeikka, Viinamaki, Polkki, \& Lehtonen, 2001; Mäkelä \& Mustonen, 2000; Marczinski, Combs, \& Fillmore, 2007; Okoro et al., 2004; Stahre, Brewer, Fonseca, \& Naimi, 2009). Variability in drinking levels is associated with a considerable heterogeneity in the accompanying effects, but it has been shown that the highintensity drinkers are at a particularly high risk for negative health consequences (Patrick, Terry-McElrath, Kloska, \&
Schulenberg, 2016; White, 2017) including mental/physical health (Wen et al., 2012) and academic/occupational functioning (Read, Beattie, Chamberlain, \& Merrill, 2008). Most studies using EEG-based measures demonstrated altered ERPs and event-related oscillations in binge drinkers during cognitive tasks probing inhibitory control, working memory, verbal encoding, and oddball detection (López-Caneda et al., 2017; Petit, Maurage, Kornreich, Verbanck, \& Campanella, 2014; Rangaswamy \& Porjesz, 2014). Other ERP studies employed stimuli with emotional valence and reported decreased P3 latencies and amplitudes to faces (Ehlers et al., 2007) and prolonged ERP latencies to utterances with emotional prosody (Maurage, Pesenti, Philippot, Joassin, \& Campanella, 2009) in young binge drinkers. However, a better understanding of the association between drinking levels and the neural basis of the affective dysfunctions is still needed. The present study examined the sensitivity of behavioral and brain-based indices to the varying levels of binge drinking intensity during an emotionally evocative task. Binge drinking is considered to be a transitional stage that precedes chronic alcohol use (Enoch, 2006; Koob, 2014; McCarty et al., 2004), as it shares similar patterns of impairments with AUD in a wide range of neurocognitive functions (for review, see Petit et al., 2014). On this view, the association between blunted emotional processing and AUD could also be extended to young adults who engage in binge drinking, but such evidence is still lacking. Considering the significant overlap of corticolimbic neurocircuits recruited by emotional processing and addictive effects of alcohol, studies of binge-related neuro-affective anomalies may provide insights into the early stages of corticolimbic dysregulation associated with high episodic drinking. Those deficits may underlie the emotional difficulties, interpersonal problems, and the development of alcohol addiction in young individuals who practice heavy drinking (Gilpin \& Koob, 2008; Koob \& Volkow, 2010; Kornreich et al., 2002).

In order to probe affective responsivity, we used images depicting emotional scenes from the International Affective Picture System (IAPS; Lang, Bradley, \& Cuthbert, 2005). The IAPS is a large collection of standardized color photographs of scenes differing along the dimensions of emotional valence and arousal. We measured EEG and analyzed the signal in time-frequency domain to examine the oscillatory dynamics of affective processing as a function of drinking habits. Recent studies have applied this methodology to analyze affective modulations of the neural oscillations in theta (4-7 Hz) frequency band (for review, see Guntekin \& Başar, 2014; Knyazev, 2007; Knyazev, Slobodskoj-Plusnin, \& Bocharov, 2010). Studies using IAPS pictures in young, healthy individuals have reported greater event-related theta power for emotional (both negative and positive) relative to neutral pictures during valence judgment, with the maximum difference appearing at 200-600 ms poststimulus and over 
posterior electrode sites (Aftanas, Reva, Varlamov, Pavlov, \& Makhnev, 2004; Aftanas, Varlamov, Pavlov, Makhnev, \& Reva, 2001, 2002; Balconi, Brambilla, \& Falbo, 2009). Greater theta responses to emotional relative to neutral visual stimuli may reflect the key role of theta oscillations in integrating affective with cognitive aspects such as attentional and mnemonic operations during processing of emotionally evocative images (Knyazev, 2007; Knyazev et al., 2010). Indeed, intracerebral laminar recordings in humans indicate that theta oscillations are primarily generated in superficial cortical layers and may reflect widespread integration across different cortical areas (Halgren et al., 2015; Wang, Ulbert, Schomer, Marinkovic, \& Halgren, 2005). These connections also extend to subcortical structures, notably the hippocampus and amygdala, so theta rhythmic activity may underlie corticolimbic interactions that mediate cognitive and emotional processes (Başar, Başar-Eroğlu, Karakaş, \& Schürmann, 1999; Hyman, Zilli, Paley, \& Hasselmo, 2005; Paré, 2003). Theta oscillations are particularly vulnerable to both acute and chronic effects of alcohol as demonstrated by reduced theta power during demanding cognitive tasks, including working memory, salience detection, inhibitory control, and response conflict (Boha et al., 2009; Jones et al., 2006; Kamarajan et al., 2004; Kamarajan et al., 2012; Kovacevic et al., 2012; Krause et al., 2002; Marinkovic, Rosen, Cox, \& Kovacevic, 2012; Pandey et al., 2016; Pandey, Kamarajan, Rangaswamy, \& Porjesz, 2012; Rangaswamy \& Porjesz, 2014). Additionally, given their genetic link with alcohol dependence, disturbances in theta oscillations have been suggested as a promising endophenotype for susceptibility to alcohol addiction (Porjesz \& Rangaswamy, 2007; Porjesz et al., 2005). In light of the sensitivity of theta to emotionally valenced stimuli and to alcohol-induced effects in the cognitive domain, this study focused on theta changes during the processing of IAPS affective picture categories as a function of heavy episodic (binge) alcohol consumption. Participants were shown images of negative, positive, erotic, and neutral scenes and were asked to rate the valence and intensity of the emotions induced by the pictures. It was hypothesized that emotionally specific theta power would be weaker in individuals who engaged in binge drinking, especially those who reported high-intensity drinking patterns.

\section{Method}

\section{Participants}

Participants in this study were 64 young, healthy adults (average age $23.3 \pm 3.3$ years, age range: $18-30$ years, 32 females). They were all right-handed and reported no drug use or cigarette smoking for at least 1 month prior to the study, no history of seizures, brain injury, neurological or neuropsychiatric disorders, no vision or hearing problems or learning difficulties, and were not taking any medications at the time of the study. Based on the information they provided on their current and recent drinking patterns during screening, which included the number of binge-drinking episodes in the past 6 months, they were divided into binge drinking (BD) and light drinking (LD) groups. The BD group comprised 32 participants who reported at least five binge episodes in the past 6 months. A binge episode was defined as consuming at least six (males) or five (females) drinks within a 2-hour time span. This criterion for defining a binge episode was adopted based on empirical evidence suggesting that this level of drinking is more likely to result in blood alcohol concentration (BAC) of $0.08 \%$ or above (Lange \& Voas, 2001). Another 32 participants who reported no more than one binge episode in the last 6 months were assigned to an LD group (please see Table 1 for details on group characteristics). The two groups were matched on age, gender, education, ethnicity/race, and percentage of participants reporting positive family history of alcoholism. As described in further detail below and in Table 1, the BD group reported higher levels of drinking and scored higher on all alcohol-related variables, as well as depression and impulsivity. However, no group differences were found on personality dimensions or performance on cognitive tasks. An additional 215 potential participants were excluded during screening because of marijuana use (54\%), smoking tobacco $(17 \%)$, current neuropsychiatric disorders $(6 \%)$, or a combination of factors $(23 \%)$.

\section{Procedure}

Upon enrollment, participants completed an extensive battery of questionnaires that probed their handedness (Oldfield, 1971), medical history, and drinking habits, including the frequency and quantity of alcohol consumption (modified from Cahalan, Cisin, \& Crossley, 1969), the magnitude of response to alcohol (Self-Rating of the Effects of Alcohol, SRE; Schuckit, Smith, \& Tipp, 1997), the severity of alcoholismrelated symptoms (Self-Administered Short Michigan Alcoholism Screening Test, SMAST; Selzer, Vinokur, \& Van Rooijen, 1975), motives for engaging in alcohol use (Drinking Motive Questionnaire Revised Short Form, DMQR SF; Kuntsche \& Kuntsche, 2009), and the consequences of drinking (Brief Young Adult Alcohol Consequences Questionnaire, B-YAACQ; Kahler, Strong, \& Read, 2005). A modified version of the Family History Assessment Module (FHAM; Rice et al., 1995) was administered to categorize participants as family history negative (FHN; those with no biological relatives reported as problematic drinkers or alcoholics), family history positive (FHP; alcoholism was reported in at least one first-degree and one first-degree or second-degree relative, or in at least three second-degree relatives), or undefined (participants who did not meet the 
Table 1 Subject characteristics $(M \pm S D$ or $n \%)$ for the BD and LD group

\begin{tabular}{|c|c|c|c|}
\hline & $\mathrm{BD}(n=32)$ & $\mathrm{LD}(n=32)$ & $p$ \\
\hline \multicolumn{4}{|l|}{ Demographics } \\
\hline$\%$ Female & $50 \%$ & $50 \%$ & $\mathrm{~ns}^{\mathrm{a}}$ \\
\hline$\%$ White/Not Hispanic or Latino & $68.8 \%$ & $71.9 \%$ & $\mathrm{~ns}^{\mathrm{a}}$ \\
\hline$\%$ Current undergraduate students & $46.9 \%$ & $43.8 \%$ & $\mathrm{~ns}^{\mathrm{a}}$ \\
\hline Age & $23.2 \pm 3.3$ & $23.4 \pm 3.4$ & ns \\
\hline Age range & $18-30$ & $18-29$ & \\
\hline Education in years & $15.7 \pm 2.1$ & $16.0 \pm 2.0$ & $\mathrm{~ns}^{\mathrm{b}}$ \\
\hline Undergraduate GPA & $3.15 \pm 0.48$ & $3.44 \pm 0.37$ & .01 \\
\hline BMI & $25.02 \pm 4.05$ & $22.97 \pm 2.99$ & .03 \\
\hline \multicolumn{4}{|l|}{ Alcohol consumption } \\
\hline No. of drinking days per week/past 6 months & $3.1 \pm 1.2$ & $1.5 \pm 0.7$ & $<.001$ \\
\hline No. of drinks per occasion/past 6 months & $5.5 \pm 1.5$ & $1.8 \pm 0.8$ & $<.001$ \\
\hline No. of intoxicated occasions per month/past 6 months & $5.6 \pm 4.6$ & $2.0 \pm 1.7$ & $<.001$ \\
\hline No. of binge episodes/past 6 months & $12.7 \pm 8.1$ & $0.09 \pm 0.3$ & $<.001$ \\
\hline No. of alcohol-induced blackouts/past 6 months & $4.5 \pm 3.6$ & $0.03 \pm 0.2$ & $<.001$ \\
\hline No. of heavy drinking days/past 30 days & $6.7 \pm 5.4$ & $0.4 \pm 0.8$ & $<.001$ \\
\hline Max no. of drinks in $24 \mathrm{hrs} /$ past 30 days & $10.2 \pm 3.3$ & $3.6 \pm 2.1$ & $<.001$ \\
\hline \multicolumn{4}{|l|}{ Drinking-related variables } \\
\hline Age of drinking onset & $15.9 \pm 1.4$ & $18.5 \pm 2.1$ & $<.001$ \\
\hline$\%$ Positive family history of alcoholism & $46.9 \%$ & $43.8 \%$ & $\mathrm{~ns}^{\mathrm{a}}$ \\
\hline Alcoholism symptoms (SMAST) & $3.13 \pm 3.23$ & $0.56 \pm 0.88$ & $<.001$ \\
\hline No. of drinks needed for effects (SRE) & $5.60 \pm 1.40$ & $4.20 \pm 1.52$ & $<.001^{\mathrm{b}}$ \\
\hline \multicolumn{4}{|l|}{ Drinking motives (DMQ-R) } \\
\hline Enhancement & $2.25 \pm 0.44$ & $1.77 \pm 0.52$ & .001 \\
\hline Social & $2.55 \pm 0.44$ & $2.11 \pm 0.53$ & .001 \\
\hline Conformity & $1.41 \pm 0.48$ & $1.38 \pm 0.41$ & ns \\
\hline Coping & $1.69 \pm 0.58$ & $1.25 \pm 0.33$ & .001 \\
\hline Drinking consequences (B-YAACQ) & $10.58 \pm 5.44$ & $2.00 \pm 1.92$ & $<.001$ \\
\hline \multicolumn{4}{|l|}{ Personality variables } \\
\hline Anxiety (GAD-7) & $4.26 \pm 5.20$ & $2.38 \pm 3.21$ & .07 \\
\hline Depression (PHQ-9) & $4.58 \pm 4.88$ & $2.13 \pm 2.03$ & .05 \\
\hline \multicolumn{4}{|l|}{ Impulsivity (ABIS) } \\
\hline Attention & $1.97 \pm 0.47$ & $1.89 \pm 0.44$ & ns \\
\hline Motor & $2.15 \pm 0.61$ & $1.84 \pm 0.47$ & .04 \\
\hline Nonplanning & $2.10 \pm 0.72$ & $1.74 \pm 0.42$ & .04 \\
\hline \multicolumn{4}{|l|}{ Sensation seeking (BSSS) } \\
\hline Experience & $4.11 \pm 0.94$ & $3.92 \pm 0.81$ & ns \\
\hline Boredom & $3.82 \pm 0.81$ & $3.48 \pm 0.71$ & ns \\
\hline Thrill & $3.47 \pm 1.13$ & $3.53 \pm 1.16$ & ns \\
\hline Disinhibition & $3.79 \pm 0.81$ & $2.63 \pm 0.98$ & $<.001$ \\
\hline \multicolumn{4}{|l|}{ Personality (EPQ) } \\
\hline Neuroticism & $3.84 \pm 3.43$ & $3.44 \pm 3.36$ & ns \\
\hline Psychoticism & $2.45 \pm 2.06$ & $2.28 \pm 1.63$ & ns \\
\hline Extraversion & $9.61 \pm 2.38$ & $8.22 \pm 3.50$ & ns \\
\hline Lie & $4.29 \pm 2.48$ & $4.75 \pm 2.99$ & ns \\
\hline \multicolumn{4}{|l|}{ Cognitive battery } \\
\hline \multicolumn{4}{|l|}{ NIH Toolbox Cognitive Tests (age-corrected standard scores) } \\
\hline Working Memory/List Sorting & $107.66 \pm 13.01$ & $104.01 \pm 13.26$ & $\mathrm{~ns}^{\mathrm{b}}$ \\
\hline Cognitive flexibility/DCCS & $104.74 \pm 9.38$ & $108.39 \pm 8.05$ & ns \\
\hline Processing Speed/Pattern Comparison & $129.14 \pm 14.35$ & $132.71 \pm 18.40$ & $\mathrm{~ns}^{\mathrm{b}}$ \\
\hline Episodic Memory/PSM & $113.89 \pm 15.08$ & $115.08 \pm 12.72$ & ns \\
\hline
\end{tabular}

${ }^{\mathrm{a}}$ Chi-square test; ${ }^{\mathrm{b}}$ independent-sample $t$ test. All other comparisons performed with the Mann-Whitney $U$ test. ns $=$ nonsignificant

criteria for either negative or positive family history) group. There were no group differences in the distribution of family history of alcoholism. The attention, motor, and nonplanning dimensions of impulsivity traits were assessed with an Abbreviated Impulsiveness Scale (ABIS; Coutlee, Politzer, Hoyle, \& Huettel, 2014). In addition, they completed questionnaires measuring personality (Eysenck Personality Questionnaire, EPQ; Eysenck, Eysenck, \& Barrett, 1985), depression (9-item Patient Health Questionnaire, PHQ-9; Kroenke \& Spitzer, 2002), anxiety (7-item anxiety scale, GAD-7; Spitzer, Kroenke, Williams, \& Lowe, 2006), and sensation seeking (Brief Sensation Seeking Scale, BSSS; Hoyle, Stephenson, Palmgreen, Lorch, \& Donohew, 2002). The participants also completed the NIH Toolbox Cognitive Battery that included the List Sorting Working Memory Test to assess working memory capacity, Dimensional Change Card Sort 
(DCCS) Test to assess cognitive flexibility, Pattern Comparison Processing Speed Test to measure processing speed, and Picture Sequence Memory (PSM) Test, which probed episodic memory (Gershon et al., 2013).

Upon arrival to the lab, participants were asked about their compliance with the request to refrain from consuming any alcohol for at least 48 hours prior to the experiment. All participants tested negative on a 12-panel urine multidrug test (American Screening Corporation, USA). They filled out the Timeline Follow-Back (TLFB) scale (Sobell \& Sobell, 1992), in which they estimated the quantity and frequency of their alcohol consumption during the past 30 days prior to the experiment. They also reported the number of heavy drinking days within the last 30 days, defined as at least six (males) or at least five (females) drinks within 24 hrs. Participants practiced the task and were fitted with an electrocap to record the scalp EEG signal while they performed an emotional rating task. At the end of the experiment, participants were debriefed and compensated for their participation.

\section{Material}

The stimulus set consisted of 352 color pictures, with 88 pictures from each of the negative, positive, erotic, and neutral categories. Most of the pictures $(\sim 80 \%)$ were selected from the International Affective Picture System (IAPS; Lang et al., 2005). Images with the highest arousal ratings from the negative and positive categories as well as those with the lowest arousal ratings from the neutral category were selected. Additional pictures were obtained from the Geneva Affective Picture Database (GAPED; Dan-Glauser \& Scherer, 2011), the picture database from Schaefer, Pottage, and Rickart (2011), or Internet sources. Five raters (three males) who did not participate in the study were requested to rate their impressions of the visual complexity based on the relative number of different visual elements of each picture on a scale ranging from 1 (very simple) to 9 (very complex). Pictures were rated as being moderately visually complex and were equated across the negative $(M=4.17, S D=1.14)$, positive $(M=4.22, S D=.95)$, and neutral photos $(M=4.18$, $S D=1.03)$, with all paired-sample $t$ test $p \mathrm{~s}>.55$. However, erotic pictures $(M=3.45, S D=.80)$ were rated as being less visually complex than other categories, $p s<.008$. These raters were also asked to provide valence and arousal ratings for the additional pictures and a subset of the standard IAPS set on a 9-point Likert scale. This assured consistency with standard ratings, with all $p \mathrm{~s}>.50$ based on independent-sample $t$ tests.

The valence scores were obtained on a bidirectional scale ranging from 1 (completely unpleasant) to 9 (completely pleasant), while the arousal scores were obtained by asking the subjects to rate how excited versus calm each picture made them feel on a scale ranging from 1 (completely calm) to 9 (completely excited) (Lang et al., 2005). Independent-sample $t$ tests performed on valence ratings combined across all sources indicated that the negative, positive, erotic, and neutral categories differed in a manner consistent with their categorization, $p \mathrm{~s}<.001$. Positive pictures were rated as more pleasant than those with erotic content, $p<.001$. All emotional pictures had higher arousal ratings than the neutral set, $p \mathrm{~s}<$ .001 . The arousal scores for erotic and negative pictures were both rated as more arousing than positive pictures, $p s<.001$ (please see Fig. 1 for average rating scores on valence and arousal of each category). This profile is consistent with other reports (Bradley, Codispoti, Cuthbert, \& Lang, 2001; Bradley \& Lang, 1994). The presence of human faces was balanced across emotional categories except for the erotic category that contained human faces in all pictures. All pictures were standardized and resized to $1024 \times 768$ pixels/inch.

\section{Task description}

The experiment was conducted with a PC using the Presentation software (Neurobehavioral Systems Inc.). During the recording, each trial started with a fixation cross presented for $1,000 \pm 250 \mathrm{~ms}$. Pictures were presented for $1,000 \mathrm{~ms}$ in the center of a 24 -inch color monitor subtending a visual angle of $6.0^{\circ} \times 4.5^{\circ}$ at a viewing distance of $180 \mathrm{~cm}$. Participants were instructed to attentively view each picture and judge how it made them feel. After the offset of each image, a 9-point visual Likert scale ranging from 1 (very negative) to 9 (very positive) was presented for $2,700 \mathrm{~ms}$ prompting participants to provide their ratings with a joystick. Pictures were presented in a randomized order in eight blocks, with 44 pictures per block. Care was taken to equate pictures for valence and arousal across blocks. Digital event markers were sent out to the EEG acquisition system simultaneously with each picture presentation. Prior to the recording, participants practiced the rating task with an additional 20 pictures that were not used during the actual experiment.

\section{EEG recording}

EEG signals were recorded from a 64-channel actiCHamp DC Brain Vision system (Brain Products $\mathrm{GmbH}$, Germany) and were continuously sampled at $500 \mathrm{~Hz}$. The nose served as the reference and an electrode attached to forehead as ground. Eyeblinks and eye movements were monitored with bipolarly referred electrodes attached above and below the left eye. The electrode impedance was maintained below $5 \mathrm{k} \Omega$.

\section{Data processing and analysis}

EEG data were analyzed with custom-written MATLAB (MathWorks, Natick, MA) routines and included modules from publicly available packages, including Fieldtrip (Oostenveld, Fries, Maris, \& Schoffelen, 2011), and 


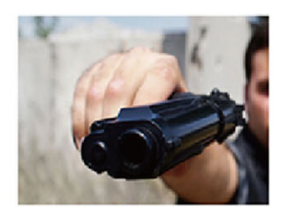

Negative

Valence: $2.37 \pm 0.61$

Arousal: $6.23 \pm 0.49$

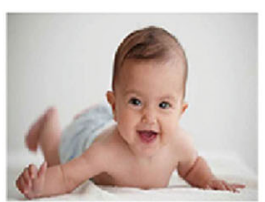

Positive

$7.20 \pm 0.41$

$5.60 \pm 0.57$

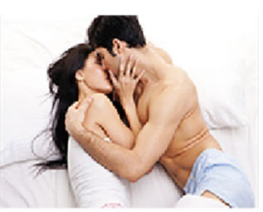

Erotic

$6.51 \pm 0.49$

$6.39 \pm 0.55$

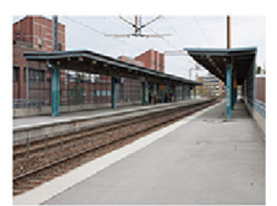

Neutral

$5.23 \pm 0.50$

$3.38 \pm 0.33$

Fig. 1 Examples and valence and arousal rating scores $(M \pm S D)$ of pictures selected from the negative, positive, erotic, and neutral categories obtained on a 1-9 Likert scale

EEGLAB (Delorme \& Makeig, 2004). The continuous EEG data were filtered with a bandpass of 0.1 to $100 \mathrm{~Hz}$ and segmented into epochs extending from -300 to $1,000 \mathrm{~ms}$ relative to each stimulus onset. A 300-ms long padding was added to each end of the epoch to account for edge artifacts during the wavelet analysis. The data were carefully inspected, and those trials that contained obvious artifacts or other discontinuities were rejected. Next, an independent component analysis was used to detect and remove artifacts caused by eyeblinks and heartbeat (Delorme \& Makeig, 2004). Complex power spectra were calculated for each trial using Morlet wavelets (Oostenveld et al., 2011) in theta range (4-7 Hz) in $1 \mathrm{~Hz}$ increments. Wavelet length was $500 \mathrm{~ms}$, and wavelength width varied from two to four cycles for all frequencies within the theta range. Theta band wavelet results were visually inspected, and any additional trials that were contaminated by artifacts were rejected. Analysis of the raw theta power in the baseline showed no group or condition differences, indicating that any observed stimulus-related differences were due to event-related changes in theta power and not to the overall differences in the baseline.

Event-related theta power was averaged across theta band frequencies $(4-7 \mathrm{~Hz})$ and across trials for each condition, and was expressed as percentage signal change from the average theta power during the -300 -ms to 0 -ms prestimulus baseline. To examine signal distribution across the scalp, the data were averaged into frontal (comprising AFz, AF3, AF4, Fz, F1, F2, F3, F4, F5, F6), central (FCz, FC1, FC2, FC3, FC4, FC5, $\mathrm{FC} 6, \mathrm{Cz}, \mathrm{C} 1, \mathrm{C} 2, \mathrm{C} 3, \mathrm{C} 4, \mathrm{C} 5, \mathrm{C} 6)$, and parietal (CPz, CP1, CP2, CP3, CP4, CP5, CP6, Pz, P1, P2, P3, P4, P5, P6) electrode clusters (see Fig. 3). The event-related theta power for each electrode cluster was averaged within time windows capturing the overall peak activity. A mixed-design analysis of covariance (ANCOVA) with group (LD vs. BD) and gender as between-subject factors, emotion (negative, positive, erotic, neutral) as a within-subject factor, and self-rated scores on anxiety, depression, motor and nonplanning impulsiveness, and disinhibition (tendency to disinhibit socially unacceptable sensation-seeking behaviors) as covariates was conducted on the emotional rating scores. With respect to the brain data, an ANCOVA with group and gender as between-subject measures, emotion and region (frontal, central, parietal) as within-subject factors, and the nondrinking dispositional covariates depicted above were carried out on event-related theta power change. These covariates were chosen because group differences were observed on these personality variables (see Table 1). Bonferroni correction was applied to limit family-wise error rates across all the statistical tests to 0.05 (i.e., for each hypothesis, the $\alpha$ level of .05 was divided by the number of comparisons). Group differences in dispositional variables and NIH-Toolbox results were evaluated with independent-sample $t$ tests when the data were normally distributed and with Mann-Whitney $U$ test for the variables that violated the assumption of normal distribution. Chi-square was calculated for categorical variables such as gender and race/ethnicity.

\section{Results}

\section{Demographic, alcohol use, personality, and cognitive variables}

As shown in Table 1, BD and LD groups were equated on age, gender, education, and race/ethnicity. However, significant group differences were observed on all variables associated with alcohol use as $\mathrm{BD}$ individuals reported consuming more alcohol, more binge episodes, and more alcohol-related blackouts in the past 6 months. Furthermore, the BD group reported that they started drinking at an earlier age; reported more alcoholism-related symptoms; greater number of drinks needed for intoxicating effects; stronger enhancement, social, and coping motives for drinking; and more negative consequences of alcohol use within the past month than the LDs. BD group also reported higher levels of motor and nonplanning impulsiveness, disinhibition, lower GPA, and a trend toward higher anxiety and depression compared to LDs. No group differences were observed on personality questionnaires, working memory, cognitive flexibility, processing speed, or episodic memory dimensions, as assessed by the NIH Toolbox Cognitive Battery.

Spearman's rank correlation coefficients were calculated between alcohol-consumption-related variables and other self-reported measures. For the BD group, the number of binge drinking episodes during the past 6 months was positively correlated with their conformity motives for alcohol 
consumption, $r_{\mathrm{s}}(30)=.44, p=.01$, indicating that the stronger the motives to conform to the peer-group pressure to drink, the more frequently the individuals engaged in binge drinking. Furthermore, the self-reported levels of anxiety and depression were both positively correlated with variables associated with the frequency, amount, and adverse consequences of alcohol consumption, all $r_{\mathrm{s}}(30)>.43, p \mathrm{~s}<.02$. These results implied that among individuals with a history of heavy episodic (binge) drinking, those with higher emotional distress (i.e., anxiety, depression) were more likely to be involved in excessive alcohol use and experience alcohol-related problems, although causality cannot be inferred.

\section{Behavioral task performance}

Subjective ratings were submitted to a mixed-design ANCOVA, and the Greenhouse-Geisser correction was applied to mitigate violations of the sphericity assumption. The results (see Fig. 2) revealed a main effect of emotion, $F(3$, $165)=39.11, p<.001, \eta_{\mathrm{p}}{ }^{2}=.42$, which was due to expected differences in picture ratings. The follow-up comparisons showed that positive pictures were rated as evoking more positive feelings than the erotic pictures were, $t(63)=3.51, p$ $<.001, d=.44$, which, in turn, were rated as more positive than the neutral ones, $t(63)=9.48, p<.001, d=1.19$. The negative pictures were rated as more negative than the neutral category pictures were, $t(63)=-51.49, p<.001, d=-6.44$. A Gender $\times$ Emotion interaction, $F(3,165)=3.86, p=.04, \eta_{\mathrm{p}}{ }^{2}=$ .07 , was a result of more positive ratings for erotic pictures given by male participants, $t(62)=2.27, p=.03, d=.57$, but this comparison did not survive the Bonferroni adjustment. There were neither differences between LD and BD groups, $F(1,55)=.03, p=.86, \eta_{\mathrm{p}}^{2}=.001$, nor a Group $\times$ Emotion

\section{Subjective rating scores}

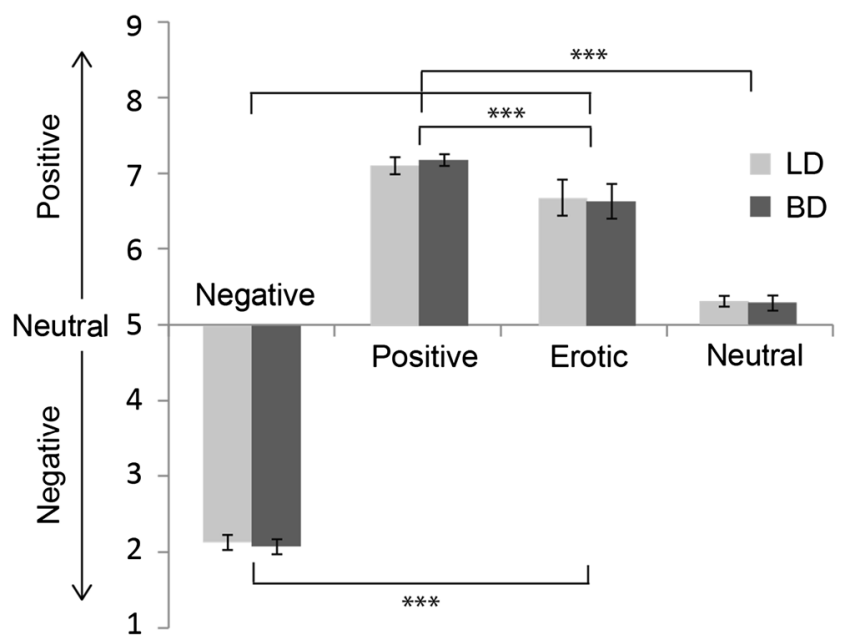

Fig. 2 Average subjective ratings for pictures in the emotional rating task. Differences in ratings are indicated as follows: $* * * p<.001$. No differences between LD and BD groups were observed interaction, $F(3,165)=.22, p=.75, \eta_{\mathrm{p}}^{2}=.004$, while controlling for the five dispositional covariates.

\section{Event-related theta}

Event-related theta power expressed as percentage change from baseline is shown for all four picture conditions for $\mathrm{BD}$ and LD groups in Fig. 3. Theta power was sensitive to the emotional categories, with greatest differences apparent during a $200-600 \mathrm{~ms}$ poststimulus time interval. For both groups, erotic photos elicited the strongest theta, peaking at $\sim 400 \mathrm{~ms}$. The negative and positive photos elicited bimodal theta reactivity with an early peak at $\sim 250 \mathrm{~ms}$, which was especially prominent in LDs, followed by a subsequent theta power increase peaking within $\sim 500-600 \mathrm{~ms}$. The pattern of theta activity to different emotional pictures was similar across frontal, central, and parietal electrode sites.

The event-related theta power was examined with an overall mixed-model ANCOVA during a 200-600-ms interval, with group and gender as between-group and emotion and region as within-subject factors, and five disposition variables serving as covariates as described in the Method section. The analyses yielded a marginally significant main effect of emotion, $F(3,165)=2.25, p=.08, \eta_{\mathrm{p}}{ }^{2}=.04$, as the event-related theta power was the greatest for pictures with erotic themes, followed by negative, positive, and neutral images across the brain, with all stepwise comparisons $p \mathrm{~s}<.001,|d \mathrm{~s}|>.44$. There was also a marginally significant Group $\times$ Emotion interaction, $F(3,165)=2.37, p=.07, \eta_{\mathrm{p}}^{2}=.04$. However, there were no other two-way, three-way, or four-way interactions between the factors of group, gender, emotion, and region, or the main effect of group, gender, or region, $p s>.24$, $\eta_{\mathrm{p}}{ }^{2} \mathrm{~s}<.03$, after controlling for anxiety, depression, motor and nonplanning impulsiveness, and disinhibition levels. Since the factors of gender and of region did not modulate the effects of group and emotion on theta, the subsequent analyses focused on parietal sites, which showed the most prominent emotional impact on theta activity as shown in Fig. 3. To further compare the two drinking groups on event-related theta induced by each emotional category, theta power change in each condition was then submitted to ANCOVAs, with the group factor and the aforementioned dispositional covariates. The results indicated that there were no group differences in the overall theta power in response to negative, $F(1,57)=.58, p=.45 \eta_{\mathrm{p}}{ }^{2}$ $=.01$; positive, $F(1,57)=.07, p=.80, \eta_{\mathrm{p}}{ }^{2}=.001$; erotic, $F(1$, $57)=.12, p=.73, \eta_{\mathrm{p}}{ }^{2}=.002$; and neutral pictures, $F(1,57)=$ $2.57, p=.12, \eta_{\mathrm{p}}{ }^{2}=.04$. Finally, to investigate the emotional modulations in event-related theta separately for each group, paired-sample $t$ tests were carried out which indicated that for the LD group, the event-related theta power decreased from erotic, negative, positive, to neutral pictures, with all pairwise comparisons, $p \mathrm{~s}<.001, d \mathrm{~s}>.73$. For the $\mathrm{BD}$ group, erotic pictures elicited the greatest theta compared to the other 


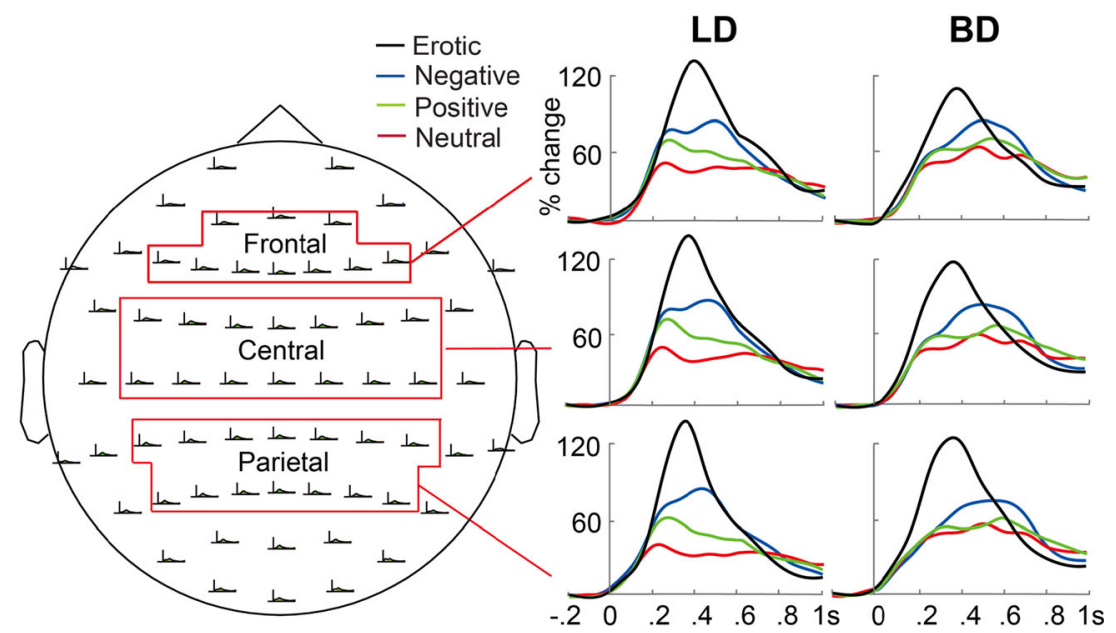

Fig. 3 Event-related theta power expressed as percent change from the baseline at different electrode sites during the emotional rating task for the LD (light drinking) and BD (binge drinking) groups. (Color figure online)

emotions, $p \mathrm{~s}<.001, d \mathrm{~s}>.86$, but the theta to other three emotional categories did not differ after Bonferroni correction, $p \mathrm{~s}>.01,|d \mathrm{~s}|<.48$.

To investigate emotion-specific modulation of theta activity to emotional relative to neutral condition, difference scores were calculated by subtracting theta power elicited by neutral pictures from those elicited by emotional (negative, positive, erotic) pictures during the 200-600-ms time interval see (Fig. 4a). A marginally significant main effect of emotion, $F(2,114)$ $=2.56, p=.08, \eta_{\mathrm{p}}{ }^{2}=.04$, replicated emotional modulations of theta with Erot-Neut $>$ Neg-Neut $>$ Pos-Neut, $p \mathrm{~s}<.001, d \mathrm{~s}>$ 1.50. More importantly, there was a main effect of group, $F(1$, $57)=5.44, p=.02, \eta_{\mathrm{p}}{ }^{2}=.09$, resulting from greater theta power to emotional relative to neutral pictures in the LD compared to BD group, even after controlling for anxiety, depression, motor and nonplanning impulsivity, and disinhibition levels. The LD group was more sensitive than $\mathrm{BD}$ to emotional modulation for negative versus neutral pictures, $F(1,57)=$ $8.29, p=.006, \eta_{\mathrm{p}}{ }^{2}=.13$, with the same trend for positive versus neutral pictures, $F(1,57)=3.19, p=.08, \eta_{\mathrm{p}}{ }^{2}=.05$, after controlling for the five personality covariates. There were no group differences for the differential theta to erotic versus neutral images, $F(1,57)=2.01, p=.16, \eta_{\mathrm{p}}^{2}=.03$. Spearman's rank correlation analysis carried out for the BD group indicated that the emotion-induced theta power difference averaged across negative and positive photos correlated negatively with the number of binge occasions within the past 6 months, $r_{\mathrm{s}}(30)$ $=-.38, p=.03$. These observations suggest that $\mathrm{BD}$ participants with more recent binge episodes might be less sensitive to emotional valence. Correlations between the emotioninduced theta difference and other dispositional attributes or alcohol-related variables in BD group did not reach significance.

Potential lateralization of neural activity was examined with a 2 (group: $\mathrm{BD}, \mathrm{LD}) \times 4$ (emotion: negative, positive, erotic, neutral) $\times 2$ (hemisphere: left, right) ANOVA on theta power from left (CP3, CP5, P3, P5) and right (CP4, CP6, P4, P6) parietal sites during the 200-600-ms epoch. The results showed a main effect of hemisphere, $F(1,186)=14.77, p<$ $.001, \eta_{\mathrm{p}}{ }^{2}=.07$, due to larger event-related theta power at the right relative to the left locations overall. However, there were no interactions between hemisphere and emotion, $F(3,186)=$ $1.62, p=.19, \eta_{\mathrm{p}}^{2}=.03$, or group factor, $F(1,62)=2.07, p=$ $.16, \eta_{\mathrm{p}}^{2}=.03$, or three-way interaction, $F(3,186)=2.05, p=$ $.11, \eta_{\mathrm{p}}{ }^{2}=.03$.

\section{Comparisons between high-BD and low-BD subgroups}

It has been well documented that there is a considerable variability among binge drinkers in their consumption patterns and the associated consequences (Read et al., 2008). Therefore, we examined potential association of highintensity versus low-intensity binge-drinking levels and theta emotional effects by refining the grouping of binge-drinking individuals. BD participants were subdivided into two subgroups with the highest and the lowest frequency of recent binge drinking, respectively. Low-level binge drinkers (BDL, $n=17,53 \%$ males) reported 10 or fewer binge episodes, $6.5 \pm 2.2$, on average over the previous 6 months. Highintensity binge drinkers (BD-H, $n=15,47 \%$ males) reported 12 or more binge episodes, averaging $19.7 \pm 5.8$, during the same period. In addition to binge episodes, the BD-H reported higher levels of conformity drinking motives than the BD-L subgroup did, $U=63.50, p=.02, r=.42$. A Group $\times$ Emotion ANCOVA was performed on the emotion-induced event-related theta change within the 200-600-ms window for the LD group and both BD subgroups with the abovementioned nondrinking dispositional covariates (see Fig. 4b). A main effect of group, $F(2,56)=4.02, p=.02, \eta_{\mathrm{p}}^{2}=.13$, was due to a lower emotional modulation of theta for BD-Hs in contrast to LDs, $F(1,40)=6.18, p=.02, \eta_{\mathrm{p}}{ }^{2}=.13$. Follow-up analyses explored the effects of emotional valence on theta, indicating 

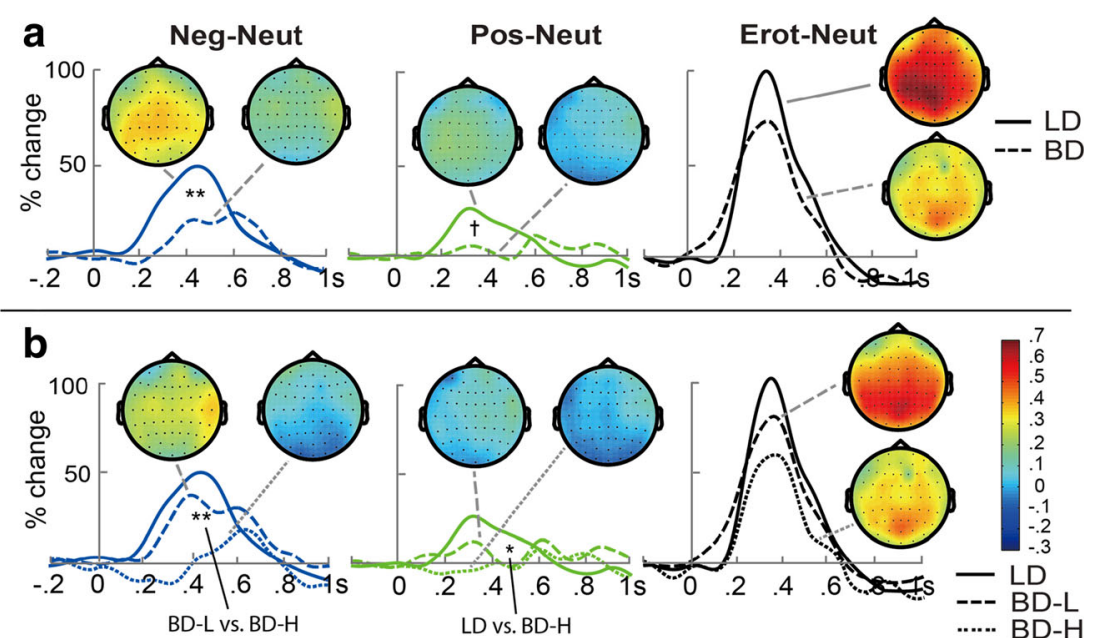

Fig. 4 Emotion-induced event-related theta differences (emotional neutral) within 200-600 ms over parietal electrode sites and the topological plots during the same time window. a Overall comparisons between
BD and LD groups. b Comparisons between LD, low-level binge drinking (BD-L), and high-intensity binge drinking (BD-H) group. $+p<.10$, $* p<.05, * * p<.01$. (Color figure online) that the power of theta to negative, $F(1,40)=16.94, p<.001$, $\eta_{\mathrm{p}}{ }^{2}=.30$, and positive photos, $F(1,40)=4.50, p=.04, \eta_{\mathrm{p}}{ }^{2}=$ .10 , was weaker for BD-H participants as compared to the $\mathrm{LD}$ group while controlling for the dispositional covariates, but the last group comparison did not survive Bonferroni adjustment. The differential theta to negative versus neutral pictures was smaller in BD-H as compared to BD-L subgroup, $t(30)=$ $-2.95, p=.006, d=-1.04$. In contrast, the BD-L group did not differ from LDs on any comparison of theta to emotional relative to neutral conditions, $p \mathrm{~s}>.24, \eta_{\mathrm{p}}{ }^{2}<.04$. No Group $\times$ Emotion interaction was observed, $F(4,112)=.64, p=.57$, $\eta_{\mathrm{p}}^{2}=.02$.

\section{Discussion}

The present study examined modulations of event-related theta power in response to emotionally evocative images in young adults differing in their drinking patterns. Greater theta power was elicited by emotional compared to neutral pictures overall with the maximal effects taking place at $\sim 200-600 \mathrm{~ms}$, in agreement with other evidence of theta power in response to IAPS pictures (Aftanas et al., 2004; Aftanas et al., 2001, 2002; Balconi, Grippa, \& Vanutelli, 2015). Of particular interest was to compare behavioral and brain-based indices of emotional processing in young adults who engage in heavy episodic (binge) drinking versus those who drink moderately. The two groups did not differ in their ratings of the emotional images, suggesting comparable subjective perception across a wide range of picture valence and salience. However, the sensitivity of event-related theta to emotional salience was diminished in binge drinkers, which was most pronounced for negative and positive emotions. The attenuated affective modulations in theta power was negatively correlated with the number of self-reported binge episodes within the past 6 months among the binge-drinking participants, possibly suggesting cumulative effects of high-intensity episodic drinking. The divergence in the group differences between the behavioral and neural data suggests that the cortical theta oscillations may serve as a sensitive neural marker of the subtle brain dysfunctions in young, healthy binge drinkers, even when no behavioral manifestations are evident. Furthermore, we observed group differences in certain aspects of trait impulsiveness (i.e., motor and nonplanning) and the disinhibition dimension of sensation seeking, along with a tendency toward higher depression and anxiety in the BD group. The observed association between frequent binge episodes and the symptoms of anxiety, depression, impulsivity, and disinhibition are consistent with previous similar reports in young binge drinkers (Balodis, Potenza, \& Olmstead, 2009; Bonin, McCreary, \& Sadava, 2000; Marczinski et al., 2007; Paljarvi et al., 2009). However, the current study showed that the binge-related affective theta deficits remained significant, even after controlling for these dispositional variables. In tandem with the nonsignificant correlations between emotioninduced theta power and these variables, the present results substantiate the view that the suppressed affective theta in binge drinkers is independent of the potentially confounding effects of neuropsychiatric symptoms like depression, anxiety, or impulsivity.

Event-related theta power to erotic pictures did not differ between the BD and LD groups. However, it was differentially sensitive to negative and positive versus neutral pictures in the LD but not in the BD group. This was already visible in the early theta modulation peaking at $\sim 250 \mathrm{~ms}$, which may reflect the orientation of attention toward emotionally salient and therefore potentially important events (Halgren \& Marinkovic, 1995). This early rapid appraisal stage may serve 
to mobilize resources to evaluate the situation and react as necessary and may facilitate easier encoding of the emotionally relevant stimuli. Previous evidence indicates that acute alcohol intoxication selectively abolishes the arousal-related orienting response to novel sounds (Marinkovic, Halgren, \& Maltzman, 2001), and the amplitudes of N2b/P3a complex to facial emotional expressions is reduced in individuals with AUD (Maurage, Campanella, Philippot, Vermeulen, et al., 2008). In addition, alcohol-related defects in orienting responses to salient nonalcohol stimuli are likely associated with the alterations in the frontoparietal attentional orienting and selection systems, which may also contribute to the biased processing of alcohol stimuli in those diagnosed with alcohol addiction (Muller-Oehring \& Schulte, 2014). The blunted early sensitivity of theta oscillations to emotional salience in relation to binge drinking observed in the present study may provide evidence for the binge-related deficits in neural systems that support preferential orienting to stimuli that incorporate emotional information. More broadly, this finding is consistent with the evidence of attentional deficits reported for binge drinkers (Hartley, Elsabagh, \& File, 2004).

The lack of emotionally differentiated early response may further undermine the subsequent emotional and cognitive stimulus evaluation and integration of the event with semantic, mnemonic, and affective contributions (Halgren \& Marinkovic, 1995). Binge drinkers showed attenuated theta to emotional stimuli throughout the trial, indicating deficient affective and cognitive evaluation and memory encoding (Başar, Başar-Eroğlu, Karakaş, \& Schürmann, 2001; Klimesch, 1999; Klimesch, Doppelmayr, Schwaiger, Winkler, \& Gruber, 2000). Indeed, it has been shown that theta is highly sensitive to the effects of chronic excessive use of alcohol (Kamarajan et al., 2004; Kamarajan et al., 2012; Rangaswamy \& Porjesz, 2014), as well as acute intoxication (Kovacevic et al., 2012; Krause et al., 2002; Marinkovic et al., 2012) during cognitive tasks, especially under higher cognitive load (Rosen, Padovan, \& Marinkovic, 2016). Theta oscillations are sensitive to emotional salience (Aftanas et al., 2004; Aftanas et al., 2001) and are thought to underlie the long-range cortico-cortical and corticolimbic interactions implicated in cognitive and emotional processes (Başar et al., 1999; Cavanagh et al., 2011; Hyman et al., 2005; Paré, 2003). Therefore, alcoholrelated theta attenuation may reflect dysregulated integration of activity across different cortical areas as well as corticolimbic connections (Halgren et al., 2015). On this view, the neuro-affective impairments in theta may mark the transition stage between binge drinking and alcohol dependence and could be helpful in early diagnosis and prevention of alcohol-related disorders.

The neural disturbances observed in young binge drinkers are consistent with the compromised functional connectivity in the frontoparietal (Muller-Oehring \& Schulte, 2014) and corticolimbic systems that mark alcohol addiction (Koob, 2014; Koob \& Volkow, 2010). Neuroimaging studies of young binge drinkers have reported wide-range neurostructural abnormalities in cortical and subcortical regions, including frontal, parietal, cerebellar, and striatal areas, ranging from altered cortical thickness, atypical gray/white matter volumes, to disturbed dendritic complexity (Cservenka \& Brumback, 2017; Howell et al., 2013; Kvamme et al., 2016; Lisdahl, Thayer, Squeglia, McQueeny, \& Tapert, 2013; Morris, Dowell, Cercignani, Harrison, \& Voon, 2017; Squeglia et al., 2012). Structural deficits in the brain regions that are engaged during processing of emotional stimuli, such as amygdala, hippocampus, and prefrontal cortex, have also been documented in AUD (Agartz, Momenan, Rawlings, Kerich, \& Hommer, 1999; Makris et al., 2008; Oscar-Berman \& Marinkovic, 2007; Sullivan \& Pfefferbaum, 2005). They may underlie neural adaptations at the level of a corticolimbic interactive neural system indicating that instead of engaging the limbic structures such as amygdala, emotional stimuli may be processed by the prefrontal cortex instead (Marinkovic et al., 2009) but at processing inefficiency costs (Sullivan \& Pfefferbaum, 2005). The current findings of dampened affective theta in BDs align with such alcohol-induced perturbations in the interactive corticolimbic pathways. Theta oscillations play a key role in mediating synchronous interactions across cortical and subcortical structures (Hasselmo \& Stern, 2014; Klimesch et al., 2001; Paré, 2003), which has been confirmed by intracranial EEG recordings in humans (Anderson, Rajagovindan, Ghacibeh, Meador, \& Ding, 2010; Halgren et al., 2015; Wang et al., 2005). Taken together, the functional and structural deficits in the cortical and limbic structures and the anomalies in their interactions observed in binge drinkers and AUD may partially explain the impaired decoding of affective information (Dethier, El Hawa, Duchateau, \& Blairy, 2013; Foisy et al., 2007; Kornreich et al., 2013; Maurage, Campanella, Philippot, Martin, \& de Timary, 2008) and their binding into episodic memory as a consequence of acute or long-term alcohol consumption (Knowles \& Duka, 2004).

It is possible that the observed group differences in emotional theta modulations are due to preexisting vulnerabilities that precede heavy drinking. Even though our study could not address that question directly, the negative correlation between binge-drinking frequency and affective theta modulation indicates that individuals with higher levels of highintensity drinking are less sensitive to emotional valence, which is consistent with deficits across different domains (Patrick et al., 2016; Read et al., 2008). We explored these effects further by differentiating high-level binge drinkers $(\mathrm{BD}-\mathrm{H})$ from those who engage in binge drinking at moderately low levels (BD-L). The BD-Hs had smaller theta power to emotion-induced stimuli than the LD group and weaker theta for negative (vs. neutral) images than BD-Ls. These 
findings suggest that the observed theta impairments in BD-H individuals may be due to risk factors that also lead to alcohol misuse but may also be a consequence of high-intensity drinking (Ahmadi et al., 2013; Jacobus \& Tapert, 2013; Petit et al., 2014).

The present results indicate that binge drinking, primarily high-intensity drinking, is accompanied by suppressed theta responses to both negatively and positively valenced stimuli. Effective perception and comprehension of the events that contain negative or positive cues play a crucial role in self-protection, emotional regulation, and social functioning (Kornreich et al., 2002; Neuberg, Kenrick, \& Schaller, 2011). The dysfunctional recruitment of appropriate neural circuitry for rapid appraisal and selectively integrated processing of affective information in young binge drinkers is compatible with the high risk-taking tendency, emotional distress, and interpersonal difficulties in this population that have been previously documented (Bonin et al., 2000; Kuntsche et al., 2004; Laukkanen et al., 2001; Okoro et al., 2004; Stahre et al., 2009; Wechsler, Davenport, Dowdall, Moeykens, \& Castillo, 1994; Wechsler, Dowdall, Davenport, \& Castillo, 1995; Wechsler et al., 2002). Anxiety and depression are commonly associated with excessive drinking and predict alcohol abuse as they may motivate further drinking in an effort to relieve these negative states (McCaul, Hutton, Stephens, Xu, \& Wand, 2017; Pedrelli, Borsari, Lipson, Heinze, \& Eisenberg, 2016). However, the observed changes in emotional theta modulation are not mediated by dispositional variables such as anxiety and depression but correlate with high-intensity drinking levels. Therefore, binge drinking may reduce emotional responsivity, which may then increase alcohol consumption use as a coping strategy, and this, in turn, can lead to the development of alcohol use disorders (D'Hondt et al., 2014; Philippot, Kornreich, \& Blairy, 2003).

In sum, the current study investigated oscillatory brain dynamics during the processing of emotionally evocative pictures. Despite the absence of group differences in subjective picture perception, emotion-induced theta was selectively weakened among binge drinkers, particularly those who engage in high-intensity drinking. These findings indicate blunted widespread modulation of cortical processing and corticolimbic interactions that may underlie impaired emotional and social functions in young binge drinkers. They are also consistent with compromised corticolimbic affective functions that characterize alcohol addiction, inasmuch as binge drinking is considered a transitional stage toward alcohol use disorder. At the clinical level, our findings may provide implications for the diagnostic and interventional strategies, as the blunted affective theta could serve as a predictive biomarker of the development of alcohol misuse even when differences on behavioral measures are not apparent. Furthermore, these results underscore the importance of addressing emotional dysfunctions in the context of heavy drinking in young adults.
Acknowledgements This research was supported by start-up funds provided by San Diego State University College of Sciences and by a grant from the National Institutes of Health, R01-AA016624. We thank Edward Nguyen, Burke Rosen, Lauren Beaton, Laura Wagner, Rifqi Affan, Audrey Andrews, and Nicole Fong for assistance. The authors declare no conflict of interest.

\section{References}

Aftanas, L. I., Reva, N. V., Varlamov, A. A., Pavlov, S. V., \& Makhnev, V. P. (2004). Analysis of evoked EEG synchronization and desynchronization in conditions of emotional activation in humans: Temporal and topographic characteristics. Neuroscience and Behavioral Physiology, 34(8), 859-867. https://doi.org/10.1023/B: NEAB.0000038139.39812.eb

Aftanas, L. I., Varlamov, A. A., Pavlov, S. V., Makhnev, V. P., \& Reva, N. V. (2001). Event-related synchronization and desynchronization during affective processing: Emergence of valence-related time-dependent hemispheric asymmetries in theta and upper alpha band. International Journal of Neuroscience, 110(3/4), 197-219. https:// doi.org/10.3109/00207450108986547

Aftanas, L. I., Varlamov, A. A., Pavlov, S. V., Makhnev, V. P., \& Reva, N. V. (2002). Time-dependent cortical asymmetries induced by emotional arousal: EEG analysis of event-related synchronization and desynchronization in individually defined frequency bands. International Journal of Psychophysiology, 44(1), 67-82. https:// doi.org/10.1016/S0167-8760(01)00194-5

Agartz, I., Momenan, R., Rawlings, R. R., Kerich, M. J., \& Hommer, D. W. (1999). Hippocampal volume in patients with alcohol dependence. Archives of General Psychiatry, 56(4), 356-363. https://doi. org/10.1001/archpsyc.56.4.356

Ahmadi, A., Pearlson, G. D., Meda, S. A., Dager, A., Potenza, M. N., Rosen, R., ... Stevens, M. C. (2013). Influence of alcohol use on neural response to go/no-go task in college drinkers. Neuropsychopharmacology, 38(11), 2197-2208. https://doi.org/10. 1038/npp.2013.119

Anderson, K. L., Rajagovindan, R., Ghacibeh, G. A., Meador, K. J., \& Ding, M. (2010). Theta oscillations mediate interaction between prefrontal cortex and medial temporal lobe in human memory. Cerebral Cortex, 20(7), 1604-1612. https://doi.org/10.1093/cercor/ bhp223

Attwood, A. S., \& Munafo, M. R. (2014). Effects of acute alcohol consumption and processing of emotion in faces: Implications for understanding alcohol-related aggression. Journal of Psychopharmacology, 28(8), 719-732. https://doi.org/10.1177/ 0269881114536476

Balconi, M., Brambilla, E., \& Falbo, L. (2009). Appetitive vs. defensive responses to emotional cues: Autonomic measures and brain oscillation modulation. Brain Research, 1296, 72-84. https://doi.org/10. 1016/j.brainres.2009.08.056

Balconi, M., Grippa, E., \& Vanutelli, M. E. (2015). What hemodynamic (fNIRS), electrophysiological (EEG) and autonomic integrated measures can tell us about emotional processing. Brain and Cognition, 95 ,67-76. https://doi.org/10.1016/j.bandc.2015.02.001

Balodis, I. M., Potenza, M. N., \& Olmstead, M. C. (2009). Binge drinking in undergraduates: Relationships with sex, drinking behaviors, impulsivity, and the perceived effects of alcohol. Behavioural Pharmacology, 20(5/6), 518-526. https://doi.org/10.1097/FBP. 0b013e328330c779

Başar, E., Başar-Eroğlu, C., Karakaş, S., \& Schürmann, M. (1999). Are cognitive processes manifested in event-related gamma, alpha, theta and delta oscillations in the EEG? Neuroscience Letters, 259(3), 165-168. https://doi.org/10.1016/S0304-3940(98)00934-3 
Başar, E., Başar-Eroğlu, C., Karakaş, S., \& Schürmann, M. (2001). Gamma, alpha, delta, and theta oscillations govern cognitive processes. International Journal of Psychophysiology, 39(2/3), 241248. https://doi.org/10.1016/S0167-8760(00)00145-8

Boha, R., Molnar, M., Gaal, Z. A., Czigler, B., Rona, K., Kass, K., \& Klausz, G. (2009). The acute effect of low-dose alcohol on working memory during mental arithmetic: I. Behavioral measures and EEG theta band spectral characteristics. International Journal of Psychophysiology, 73(2), 133-137. https://doi.org/10.1016/j. ijpsycho.2009.02.006

Bonin, M. F., McCreary, D. R., \& Sadava, S. W. (2000). Problem drinking behavior in two community-based samples of adults: Influence of gender, coping, loneliness, and depression. Psychology of Addictive Behaviors, 14(2), 151-161. https://doi.org/10.1037// 0893-164x.14.2.151

Borrill, J. A., Rosen, B. K., \& Summerfield, A. B. (1987). The influence of alcohol on judgment of facial expressions of emotion. British Journal of Medical Psychology, 60, 71-77.

Bradley, M. M., Codispoti, M., Cuthbert, B. N., \& Lang, P. J. (2001). Emotion and motivation: I. Defensive and appetitive reactions in picture processing. Emotion, 1(3), 276-298. https://doi.org/10. 1037//1528-3542.1.3.276

Bradley, M. M., \& Lang, P. J. (1994). Measuring emotion: The selfassessment manikin and the semantic differential. Journal of Behavior Therapy and Experimental Psychiatry, 25(1), 49-59.

Cahalan, D., Cisin, I. H., \& Crossley, H. M. (1969). American drinking practices: A national study of drinking behavior and attitudes (Monograph No. 6). New Brunswick, NJ: Rutgers Center of Alcohol Studies.

Cavanagh, J. F., Wiecki, T. V., Cohen, M. X., Figueroa, C. M., Samanta, J., Sherman, S. J., \& Frank, M. J. (2011). Subthalamic nucleus stimulation reverses mediofrontal influence over decision threshold. Nature Neuroscience, 14(11), 1462-1467. https://doi.org/10.1038/ nn. 2925

Coutlee, C. G., Politzer, C. S., Hoyle, R. H., \& Huettel, S. A. (2014). An Abbreviated Impulsiveness Scale (ABIS) constructed through confirmatory factor analysis of the Barratt Impulsiveness Scale Version 11. Archives of Scientific Psychology, 2(1), 1-12. https://doi.org/10. $1037 / \operatorname{arc} 0000005$

Cservenka, A., \& Brumback, T. (2017). The burden of binge and heavy drinking on the brain: Effects on adolescent and young adult neural structure and function. Frontiers in Psychology, 8, 1111. https://doi. org/10.3389/fpsyg.2017.01111

D’Hondt, F., Campanella, S., Kornreich, C., Philippot, P., \& Maurage, P. (2014). Below and beyond the recognition of emotional facial expressions in alcohol dependence: From basic perception to social cognition. Neuropsychiatric Disease and Treatment, 10, 2177 2182. https://doi.org/10.2147/NDT.S74963

Dan-Glauser, E. S., \& Scherer, K. R. (2011). The Geneva Affective Picture Database (GAPED): A new 730-picture database focusing on valence and normative significance. Behavior Research Methods, 43(2), 468-477. https://doi.org/10.3758/s13428-011-0064-1

Delorme, A., \& Makeig, S. (2004). EEGLAB: An open source toolbox for analysis of single-trial EEG dynamics including independent component analysis. Journal of Neuroscience Methods, 134(1), 921. https://doi.org/10.1016/j.jneumeth.2003.10.009

Dethier, M., El Hawa, M., Duchateau, R., \& Blairy, S. (2013). Emotional facial expression recognition and expressivity in Type I and Type II alcohol dependent patients. Journal of Nonverbal Behavior, 38(1), 89-105. https://doi.org/10.1007/s10919-013-0161-1

Dolder, P. C., Holze, F., Liakoni, E., Harder, S., Schmid, Y., \& Liechti, M. E. (2017). Alcohol acutely enhances decoding of positive emotions and emotional concern for positive stimuli and facilitates the viewing of sexual images. Psychopharmacology, 234(1), 41-51. https:// doi.org/10.1007/s00213-016-4431-6
Ehlers, C. L., Phillips, E., Finnerman, G., Gilder, D., Lau, P., \& Criado, J. (2007). P3 components and adolescent binge drinking in Southwest California Indians. Neurotoxicology and Teratology, 29(1), 153163. https://doi.org/10.1016/j.ntt.2006.11.013

Enoch, M. A. (2006). Genetic and environmental influences on the development of alcoholism: Resilience vs. risk. Annals of the New York Academy of Sciences, 1094, 193-201. https://doi.org/10. 1196/annals.1376.019

Euser, A. S., \& Franken, I. H. (2012). Alcohol affects the emotional modulation of cognitive control: An event-related brain potential study. Psychopharmacology, 222(3), 459-476. https://doi.org/10. 1007/s00213-012-2664-6

Eysenck, S. B. G., Eysenck, H. J., \& Barrett, P. (1985). A revised version of the psychoticism scale. Personality and Individual Differences, 6(1), 21-29. https://doi.org/10.1016/0191-8869(85)90026-1

Foisy, M. L., Kornreich, C., Fobe, A., D’Hondt, L., Pelc, I., Hanak, C., ... Philippot, P. (2007). Impaired emotional facial expression recognition in alcohol dependence: Do these deficits persist with midterm abstinence? Alcoholism: Clinical and Experimental Research, 31(3), 404-410. https://doi.org/10.1111/j.1530-0277.2006.00321.x

Franken, I. H., Nijs, I. M., Muris, P., \& Van Strien, J. W. (2007). Alcohol selectively reduces brain activity during the affective processing of negative information. Alcoholism: Clinical and Experimental Research, 31(6), 919-927. https://doi.org/10.1111/j.1530-0277. 2007.00424.x

Gershon, R. C., Wagster, M. V., Hendrie, H. C., Fox, N. A., Cook, K. F., \& Nowinski, C. J. (2013). NIH Toolbox for Assessment of Neurological and Behavioral Function. Neurology, 80(11, Suppl. 3), S2-S6. https://doi.org/10.1212/WNL.0b013e3182872e5f

Gilpin, N. W., \& Koob, G. F. (2008). Neurobiology of alcohol dependence: Focus on motivational mechanisms. Alcohol Research and Health, 31(3), 185-195.

Grynberg, D., Maurage, P., \& Nandrino, J. L. (2017). Preserved affective sharing but impaired decoding of contextual complex emotions in alcohol dependence. Alcoholism: Clinical and Experimental Research, 41(4), 779-785. https://doi.org/10.1111/acer.13330

Guntekin, B., \& Başar, E. (2014). A review of brain oscillations in perception of faces and emotional pictures. Neuropsychologia, 58, 33 51. https://doi.org/10.1016/j.neuropsychologia.2014.03.014

Halgren, E., Kaestner, E., Marinkovic, K., Cash, S. S., Wang, C., Schomer, D. L.,... Ulbert, I. (2015). Laminar profile of spontaneous and evoked theta: Rhythmic modulation of cortical processing during word integration. Neuropsychologia, 76, 108-124. https://doi. org/10.1016/j.neuropsychologia.2015.03.021

Halgren, E., \& Marinkovic, K. (1995). Neurophysiological networks integrating human emotions. In M. Gazzaniga (Ed.), The cognitive neurosciences (pp. 1137-1151). Cambridge, MA: MIT Press.

Hartley, D. E., Elsabagh, S., \& File, S. E. (2004). Binge drinking and sex: Effects on mood and cognitive function in healthy young volunteers. Pharmacology Biochemistry and Behavior, 78(3), 611-619. https:// doi.org/10.1016/j.pbb.2004.04.027

Hasselmo, M. E., \& Stern, C. E. (2014). Theta rhythm and the encoding and retrieval of space and time. NeuroImage, 85(Pt. 2), 656-666. https://doi.org/10.1016/j.neuroimage.2013.06.022

Howell, N. A., Worbe, Y., Lange, I., Tait, R., Irvine, M., Banca, P., ... Voon, V. (2013). Increased ventral striatal volume in college-aged binge drinkers. PLoS ONE, 8(9), e74164. https://doi.org/10.1371/ journal.pone. 0074164

Hoyle, R. H., Stephenson, M. T., Palmgreen, P., Lorch, E. P., \& Donohew, R. L. (2002). Reliability and validity of a brief measure of sensation seeking. Personality and Individual Differences, 32(3), 401-414. https://doi.org/10.1016/S0191-8869(01)00032-0

Hyman, J. M., Zilli, E. A., Paley, A. M., \& Hasselmo, M. E. (2005). Medial prefrontal cortex cells show dynamic modulation with the hippocampal theta rhythm dependent on behavior. Hippocampus, 15(6), 739-749. https://doi.org/10.1002/hipo.20106 
Jacobus, J., \& Tapert, S. F. (2013). Neurotoxic effects of alcohol in adolescence. Annual Review of Clinical Psychology, 9, 703-721. https://doi.org/10.1146/annurev-clinpsy-050212-185610

Jones, B. T., Corbin, W., \& Fromme, K. (2001). A review of expectancy theory and alcohol consumption. Addiction, 96(1), 57-72. https:// doi.org/10.1080/09652140020016969

Jones, K. A., Porjesz, B., Chorlian, D., Rangaswamy, M., Kamarajan, C., Padmanabhapillai, A.,... Begleiter, H. (2006). S-transform time-frequency analysis of P300 reveals deficits in individuals diagnosed with alcoholism. Clinical Neurophysiology, 117(10), 2128-2143. https://doi.org/10.1016/j.clinph.2006.02.028

Kahler, C. W., Strong, D. R., \& Read, J. P. (2005). Toward efficient and comprehensive measurement of the alcohol problems continuum in college students: The Brief Young Adult Alcohol Consequences Questionnaire. Alcoholism: Clinical and Experimental Research, 29(7), 1180-1189. https://doi.org/10.1097/01.ALC.0000171940. 95813.A5

Kamarajan, C., Porjesz, B., Jones, K. A., Choi, K., Chorlian, D. B., Padmanabhapillai, A., ... Begleiter, H. (2004). The role of brain oscillations as functional correlates of cognitive systems: A study of frontal inhibitory control in alcoholism. International Journal of Psychophysiology, 51(2), 155-180. https://doi.org/10.1016/j. ijpsycho.2003.09.004

Kamarajan, C., Rangaswamy, M., Manz, N., Chorlian, D. B., Pandey, A. K., Roopesh, B. N., \& Porjesz, B. (2012). Topography, power, and current source density of theta oscillations during reward processing as markers for alcohol dependence. Human Brain Mapping, 33(5), 1019-1039. https://doi.org/10.1002/hbm.21267

Klimesch, W. (1999). EEG alpha and theta oscillations reflect cognitive and memory performance: A review and analysis. Brain Research Reviews, 29(2/3), 169-195. https://doi.org/10.1016/S01650173(98)00056-3

Klimesch, W., Doppelmayr, M., Schwaiger, J., Winkler, T., \& Gruber, W. (2000). Theta oscillations and the ERP old/new effect: Independent phenomena? Clinical Neurophysiology, 111(5), 781-793. https:// doi.org/10.1016/S1388-2457(00)00254-6

Klimesch, W., Doppelmayr, M., Yonelinas, A., Kroll, N. E., Lazzara, M., Rohm, D., \& Gruber, W. (2001). Theta synchronization during episodic retrieval: Neural correlates of conscious awareness. Cognitive Brain Research, 12(1), 33-38.

Knowles, S. K. Z., \& Duka, T. (2004). Does alcohol affect memory for emotional and non-emotional experiences in different ways? Behavioural Pharmacology, 15(2), 111-121. https://doi.org/10. 1097/00008877-200403000-00003

Knyazev, G. G. (2007). Motivation, emotion, and their inhibitory control mirrored in brain oscillations. Neuroscience and Biobehavioral Reviews, 31(3), 377-395. https://doi.org/10.1016/j.neubiorev.2006. 10.004

Knyazev, G. G., Slobodskoj-Plusnin, J. Y., \& Bocharov, A. V. (2010). Gender differences in implicit and explicit processing of emotional facial expressions as revealed by event-related theta synchronization. Emotion, 10(5), 678-687. https://doi.org/10.1037/a0019175

Koob, G. F. (2014). Neurocircuitry of alcohol addiction: Synthesis from animal models. Handbook of Clinical Neurology, 125, 33-54. https://doi.org/10.1016/B978-0-444-62619-6.00003-3

Koob, G. F., \& Volkow, N. D. (2010). Neurocircuitry of addiction. Neuropsychopharmacology, 35(1), 217-238. https://doi.org/10. 1038/npp.2009.110

Kornreich, C., Brevers, D., Canivet, D., Ermer, E., Naranjo, C., Constant, E., ... Noel, X. (2013). Impaired processing of emotion in music, faces and voices supports a generalized emotional decoding deficit in alcoholism. Addiction, 108(1), 80-88. https://doi.org/10.1111/j. 1360-0443.2012.03995.x

Kornreich, C., Philippot, P., Foisy, M. L., Blairy, S., Raynaud, E., Dan, B., ... Verbanck, P. (2002). Impaired emotional facial expression recognition is associated with interpersonal problems in alcoholism.
Alcohol and Alcoholism, 37(4), 394-400. https://doi.org/10.1093/ alcalc/37.4.394

Kovacevic, S., Azma, S., Irimia, A., Sherfey, J., Halgren, E., \& Marinkovic, K. (2012). Theta oscillations are sensitive to both early and late conflict processing stages: Effects of alcohol intoxication. PLoS ONE, 7(8), e43957. https://doi.org/10.1371/journal.pone. 0043957

Krause, C. M., Aromaki, A., Sillanmaki, L., Astrom, T., Alanko, K., Salonen, E., \& Peltola, O. (2002). Alcohol-induced alterations in ERD/ERS during an auditory memory task. Alcohol, 26(3), 145153. https://doi.org/10.1016/S0741-8329(01)00204-X

Kroenke, K., \& Spitzer, R. L. (2002). The PHQ-9: A new depression and diagnostic severity measure. Psychiatric Annals, 32, 509-521. https://doi.org/10.3928/0048-5713-20020901-06

Kuntsche, E., \& Kuntsche, S. (2009). Development and validation of the Drinking Motive Questionnaire Revised Short Form (DMQ-R SF). Journal of Clinical Child and Adolescent Psychology, 38(6), 899908. https://doi.org/10.1080/15374410903258967

Kuntsche, E., Rehm, J., \& Gmel, G. (2004). Characteristics of binge drinkers in Europe. Social Science and Medicine, 59(1), 113-127. https://doi.org/10.1016/j.socscimed.2003.10.009

Kvamme, T. L., Schmidt, C., Strelchuk, D., Chang-Webb, Y. C., Baek, K., \& Voon, V. (2016). Sexually dimorphic brain volume interaction in college-aged binge drinkers. NeuroImage: Clinical, 10, 310-317. https://doi.org/10.1016/j.nicl.2015.12.004

Lang, P. J., Bradley, M. M., \& Cuthbert, B. N. (2005). International affective picture system (IAPS): Affective ratings of pictures and instruction manual (Vol. Technical Report A-8). Gainesville: University of Florida.

Lange, J. E., \& Voas, R. B. (2001). Define binge drinking quantities through resulting blood alcohol concentrations. Psychology of Addictive Behaviors, 15(4), 310-316. https://doi.org/10.1037/ 0893-164X.15.4.310

Laukkanen, E. R., Shemeikka, S. L., Viinamaki, H. T., Polkki, P. L., \& Lehtonen, J. O. (2001). Heavy drinking is associated with more severe psychosocial dysfunction among girls than boys in Finland. Journal of Adolescent Health, 28(4), 270-277. https://doi.org/10. 1016/S1054-139x(00)00183-X

Lisdahl, K. M., Thayer, R., Squeglia, L. M., McQueeny, T. M., \& Tapert, S. F. (2013). Recent binge drinking predicts smaller cerebellar volumes in adolescents. Psychiatry Research, 211(1), 17-23. https:// doi.org/10.1016/j.pscychresns.2012.07.009

López-Caneda, E., Holguín, S. R., Correas, Á., Carbia, C., GonzÁlezVillar, A., Maestú, F., \& Cadaveira, F. (2017). Binge drinking affects brain oscillations linked to motor inhibition and execution. Journal of Psychopharmocology, 31(7), 1-10. https://doi.org/10.1177/ 0269881116689258

Mäkelä, K., \& Mustonen, H. (2000). Relationships of drinking behaviour, gender and age with reported negative and positive experiences related to drinking. Addiction, 95(5), 727-736. https://doi.org/10. 1046/j.1360-0443.2000.9557278.x

Makris, N., Oscar-Berman, M., Jaffin, S. K., Hodge, S. M., Kennedy, D. N., Caviness, V. S.,... Harris, G. J. (2008). Decreased volume of the brain reward system in alcoholism. Biological Psychiatry, 64(3), 192-202. https://doi.org/10.1016/j.biopsych.2008.01.018

Marczinski, C. A., Combs, S. W., \& Fillmore, M. T. (2007). Increased sensitivity to the disinhibiting effects of alcohol in binge drinkers. Psychology of Addictive Behaviors, 21(3), 346-354. https://doi.org/ 10.1037/0893-164X.21.3.346

Marinkovic, K., Halgren, E., \& Maltzman, I. (2001). Arousal-related P3a to novel auditory stimuli is abolished by a moderately low alcohol dose. Alcohol and Alcoholism, 36(6), 529-539. https://doi.org/10. 1093/alcalc/36.6.529

Marinkovic, K., Oscar-Berman, M., Urban, T., O’Reilly, C. E., Howard, J. A., Sawyer, K., \& Harris, G. J. (2009). Alcoholism and dampened temporal limbic activation to emotional faces. Alcoholism: Clinical 
and Experimental Research, 33(11), 1880-1892. https://oi.org/10. 1111/j.1530-0277.2009.01026.x

Marinkovic, K., Rosen, B. Q., Cox, B., \& Kovacevic, S. (2012). Eventrelated theta power during lexical-semantic retrieval and decision conflict is modulated by alcohol intoxication: Anatomicallyconstrained MEG. Frontiers in Psychology, 3(121). https://doi.org/ 10.3389/fpsyg.2012.00121

Maurage, P., Campanella, S., Philippot, P., Charest, I., Martin, S., \& de Timary, P. (2009). Impaired emotional facial expression decoding in alcoholism is also present for emotional prosody and body postures. Alcohol and Alcoholism, 44(5), 476-485. https://doi.org/10.1093/ alcalc/agp037

Maurage, P., Campanella, S., Philippot, P., Martin, S., \& de Timary, P. (2008). Face processing in chronic alcoholism: A specific deficit for emotional features. Alcoholism: Clinical and Experimental Research, 32(4), 600-606. https://doi.org/10.1111/j.1530-0277. 2007.00611.x

Maurage, P., Campanella, S., Philippot, P., de Timary, P., Constant, E., Gauthier, S.,... Verbanck, P. (2008). Alcoholism leads to early perceptive alterations, independently of comorbid depressed state: An ERP study. Neurophysiologie Clinique/Clinical Neurophysiology, 38(2), 83-97. https://doi.org/10.1016/j.neucli.2008.02.001

Maurage, P., Campanella, S., Philippot, P., Vermeulen, N., Constant, E., Luminet, O., \& de Timary, P. (2008). Electrophysiological correlates of the disrupted processing of anger in alcoholism. International Journal of Psychophysiology, 70(1), 50-62. https://doi.org/10. 1016/j.ijpsycho.2008.05.572

Maurage, P., Pesenti, M., Philippot, P., Joassin, F., \& Campanella, S. (2009). Latent deleterious effects of binge drinking over a short period of time revealed only by electrophysiological measures. Journal of Psychiatry and Neuroscience, 34(2), 111-118.

Maurage, P., Philippot, P., Verbanck, P., Noel, X., Kornreich, C., Hanak, C., \& Campanella, S. (2007). Is the P300 deficit in alcoholism associated with early visual impairments (P100, N170)? An oddball paradigm. Clinical Neurophysiology, 118(3), 633-644. https://doi. org/10.1016/j.clinph.2006.11.007

McCarty, C. A., Ebel, B. E., Garrison, M. M., DiGiuseppe, D. L., Christakis, D. A., \& Rivara, F. P. (2004). Continuity of binge and harmful drinking from late adolescence to early adulthood. Pediatrics, 114(3), 714-719. https://doi.org/10.1542/peds.20030864-L

McCaul, M. E., Hutton, H. E., Stephens, M. A., Xu, X., \& Wand, G. S. (2017). Anxiety, anxiety sensitivity, and perceived stress as predictors of recent drinking, alcohol craving, and social stress response in heavy drinkers. Alcoholism: Clinical and Experimental Research, 41(4), 836-845. https://doi.org/10.1111/acer.13350

Monnot, M., Lovallo, W. R., Nixon, S. J., \& Ross, E. (2002). Neurological basis of deficits in affective prosody comprehension among alcoholics and fetal alcohol-exposed adults. The Journal of Neuropsychiatry and Clinical Neurosciences 14(3), 321-328. https://doi.org/10.1176/jnp.14.3.321

Morris, L. S., Dowell, N. G., Cercignani, M., Harrison, N. A., \& Voon, V. (2017). Binge drinking differentially affects cortical and subcortical microstructure. Addiction Biology, 1-9. https://doi.org/10.1111/adb. 12493

Muller-Oehring, E. M., \& Schulte, T. (2014). Cognition, emotion, and attention. Handbook of Clinical Neurology, 125, 341-354. https:// doi.org/10.1016/B978-0-444-62619-6.00020-3

National Institute on Alcohol Abuse and Alcoholism. (2017). Drinking levels defined. Retrieved from http://www.niaaa.nih.gov/alcoholhealth/overview-alcohol-consumption/moderate-binge-drinking

Neuberg, S. L., Kenrick, D. T., \& Schaller, M. (2011). Human threat management systems: Self-protection and disease avoidance. Neuroscience and Biobehavioral Reviews 35(4), 1042-1051. https://doi.org/10.1016/j.neubiorev.2010.08.011
Okoro, C. A., Brewer, R. D., Naimi, T. S., Moriarty, D. G., Giles, W. H., \& Mokdad, A. H. (2004). Binge drinking and health-related quality of life: Do popular perceptions match reality? American Journal of Preventive Medicine, 26(3), 230-233. https://doi.org/10.1016/j. amepre.2003.10.022

Oldfield, R. C. (1971). The assessment and analysis of handedness: The Edinburgh inventory. Neuropsychologia, 9(1), 97-113.

Oostenveld, R., Fries, P., Maris, E., \& Schoffelen, J. M. (2011). FieldTrip: Open source software for advanced analysis of MEG, EEG, and invasive electrophysiological data. Computational Intelligence and Neuroscience, 2011, 156869. https://doi.org/10.1155/2011/156869

Oscar-Berman, M., \& Marinkovic, K. (2007). Alcohol: Effects on neurobehavioral functions and the brain. Neuropsychology Review, 17(3), 239-257. https://doi.org/10.1007/s11065-007-9038-6

Oscar-Berman, M., Valmas, M. M., Sawyer, K. S., Ruiz, S. M., Luhar, R. B., \& Gravitz, Z. R. (2014). Profiles of impaired, spared, and recovered neuropsychologic processes in alcoholism. Handbook of Clinical Neurology, 125, 183-210. https://doi.org/10.1016/b978-0444-62619-6.00012-4

Paljarvi, T., Koskenvuo, M., Poikolainen, K., Kauhanen, J., Sillanmaki, L., \& Makela, P. (2009). Binge drinking and depressive symptoms: A 5-year population-based cohort study. Addiction, 104(7), 11681178. https://doi.org/10.1111/j.1360-0443.2009.02577.x

Pandey, A. K., Kamarajan, C., Manz, N., Chorlian, D. B., Stimus, A., \& Porjesz, B. (2016). Delta, theta, and alpha event-related oscillations in alcoholics during go/no-go task: Neurocognitive deficits in execution, inhibition, and attention processing. Progress in NeuroPsychopharmacology and Biological Psychiatry, 65, 158-171. https://doi.org/10.1016/j.pnpbp

Pandey, A. K., Kamarajan, C., Rangaswamy, M., \& Porjesz, B. (2012). Event-related oscillations in alcoholism research: A review. Journal of Addiction Research and Therapy, Suppl 7(1), 1-13. https://doi. org/10.4172/2155-6105.S7-001

Paré, D. (2003). Role of the basolateral amygdala in memory consolidation. Progress in Neurobiology, 70(5), 409-420. https://doi.org/10. 1016/s0301-0082(03)00104-7

Patrick, M. E., Terry-McElrath, Y. M., Kloska, D. D., \& Schulenberg, J. E. (2016). High-Intensity drinking among young adults in the United States: Prevalence, frequency, and developmental change. Alcoholism: Clinical and Experimental Research, 40(9), 19051912. https://doi.org/10.1111/acer.13164

Pedrelli, P., Borsari, B., Lipson, S. K., Heinze, J. E., \& Eisenberg, D. (2016). Gender differences in the relationships among major depressive disorder, heavy alcohol use, and mental health treatment engagement among college students. Journal of Studies on Alcohol and Drugs, 77(4), 620-628. https://doi.org/10.15288/jsad.2016.77. 620

Petit, G., Maurage, P., Kornreich, C., Verbanck, P., \& Campanella, S. (2014). Binge drinking in adolescents: A review of neurophysiological and neuroimaging research. Alcohol and Alcoholism, 49(2), 198-206. https://doi.org/10.1093/alcalc/agt172

Philippot, P., Kornreich, C., \& Blairy, S. (2003). Nonverbal deficits and interpersonal regulation in alcoholics. In P. Philippot, R. S. Feldman, \& E. J. Coats (Eds.), Nonverbal behavior in clinical settings (pp. 209-231). New York, NY: Oxford University Press.

Philippot, P., Kornreich, C., Blairy, S., Baert, I., Den Dulk, A., Le Bon, O.,... Verbanck, P. (1999). Alcoholics' deficits in the decoding of emotional facial expression. Alcoholism: Clinical and Experimental Research, 23(6), 1031-1038. https://doi.org/10.1111/j.1530-0277. 1999.tb04221.x

Pihl, R. O., \& Sutton, R. (2009). Drugs and aggression readily mix; so what now? Substance Use \& Misuse, 44(9/10), 1188-1203. https:// doi.org/10.1080/10826080902959884

Porjesz, B., \& Rangaswamy, M. (2007). Neurophysiological endophenotypes, CNS disinhibition, and risk for alcohol 
dependence and related disorders. The Scientific World Journal, 7, 131-141. https://doi.org/10.1100/tsw.2007.203

Porjesz, B., Rangaswamy, M., Kamarajan, C., Jones, K. A., Padmanabhapillai, A., \& Begleiter, H. (2005). The utility of neurophysiological markers in the study of alcoholism. Clinical Neurophysiology, 116(5), 993-1018. https://doi.org/10.1016/j. clinph.2004.12.016

Rangaswamy, M., \& Porjesz, B. (2014). Understanding alcohol use disorders with neuroelectrophysiology. Handbook of Clinical Neurology, 125, 383-414. https://doi.org/10.1016/B978-0-44462619-6.00023-9

Read, J. P., Beattie, M., Chamberlain, R., \& Merrill, J. E. (2008). Beyond the "binge" threshold: Heavy drinking patterns and their association with alcohol involvement indices in college students. Addictive Behaviors, 33(2), 225-234. https://doi.org/10.1016/j.addbeh.2007. 09.001

Rice, J. P., Reich, T., Bucholz, K. K., Neuman, R. J., Fishman, R., Rochberg, N.,... Begleiter, H. (1995). Comparison of direct interview and family history diagnoses of alcohol dependence. Alcoholism: Clinical and Experimental Research, 19(4), 10181023.

Rosen, B. Q., Padovan, N., \& Marinkovic, K. (2016). Alcohol hits you when it is hard: Intoxication, task difficulty, and theta brain oscillations. Alcoholism: Clinical and Experimental Research, 40(4), 743 752. https://doi.org/10.1111/acer.13014

Sawyer, K. S., Poey, A., Ruiz, S. M., Marinkovic, K., \& Oscar-Berman, M. (2015). Measures of skin conductance and heart rate in alcoholic men and women during memory performance. PeerJ, 3, e941. https://doi.org/10.7717/peerj.941

Sayette, M. A., Smith, D. W., Breiner, M. J., \& Wilson, G. T. (1992). The effect of alcohol on emotional response to a social stressor. Journal of Studies on Alcohol, 53(6), 541-545.

Schaefer, A., Pottage, C. L., \& Rickart, A. J. (2011). Electrophysiological correlates of remembering emotional pictures. NeuroImage, 54(1), 714-724. https://doi.org/10.1016/j.neuroimage.2010.07.030

Schuckit, M. A., Smith, T. L., \& Tipp, J. E. (1997). The Self-Rating of the Effects of Alcohol (SRE) form as a retrospective measure of the risk for alcoholism. Addiction, 92(8), 979-988. https://doi.org/10.1046/j. 1360-0443.1997.9289797.x

Selzer, M. L., Vinokur, A., \& Van Rooijen, L. (1975). A self-administered Short Michigan Alcoholism Screening Test (SMAST). Journal of Studies on Alcohol, 36(1), 117-126.

Sher, K. J., Bartholow, B. D., Peuser, K., Erickson, D. J., \& Wood, M. D. (2007). Stress-response-dampening effects of alcohol: Attention as a mediator and moderator. Journal of Abnormal Psychology, 116(2), 362-377. https://doi.org/10.1037/0021-843X.116.2.362

Sobell, L. C., \& Sobell, M. B. (1992). Timeline Follow-Back. In R. Z. Litten \& J. P. Allen (Eds.), Measuring alcohol consumption:
Psychosocial and biochemical methods (pp. 41-72). Totowa, NJ: Humana Press.

Spitzer, R. L., Kroenke, K., Williams, J. B., \& Lowe, B. (2006). A brief measure for assessing generalized anxiety disorder: The GAD-7. Archives of Internal Medicine, 166(10), 1092-1097. https://doi. org/10.1001/archinte.166.10.1092

Squeglia, L. M., Sorg, S. F., Schweinsburg, A. D., Wetherill, R. R., Pulido, C., \& Tapert, S. F. (2012). Binge drinking differentially affects adolescent male and female brain morphometry. Psychopharmacology, 220(3), 529-539. https://doi.org/10.1007/ s00213-011-2500-4

Stahre, M. A., Brewer, R. D., Fonseca, V. P., \& Naimi, T. S. (2009). Binge drinking among U.S. active-duty military personnel. American Journal of Preventive Medicine, 36(3), 208-217. https://doi.org/ 10.1016/j.amepre.2008.10.017

Sullivan, E. V., \& Pfefferbaum, A. (2005). Neurocircuitry in alcoholism: A substrate of disruption and repair. Psychopharmacology, 180(4), 583-594. https://doi.org/10.1007/s00213-005-2267-6

Wang, C., Ulbert, I., Schomer, D. L., Marinkovic, K., \& Halgren, E. (2005). Responses of human anterior cingulate cortex microdomains to error detection, conflict monitoring, stimulus-response mapping, familiarity, and orienting. Journal of Neuroscience, 25(3), 604-613. https://doi.org/10.1523/JNEUROSCI.4151-04.2005

Wechsler, H., Davenport, A., Dowdall, G., Moeykens, B., \& Castillo, S. (1994). Health and behavioral consequences of binge drinking in college: A national survey of students at 140 campuses. JAMA, 272(21), 1672-1677. https://doi.org/10.1001/jama.1994. 03520210056032

Wechsler, H., Dowdall, G. W., Davenport, A., \& Castillo, S. (1995). Correlates of college student binge drinking. American Journal of Public Health, 85(7), 921-926. https://doi.org/10.2105/AJPH.85.7. 921

Wechsler, H., Lee, J. E., Kuo, M., Seibring, M., Nelson, T. F., \& Lee, H. (2002). Trends in college binge drinking during a period of increased prevention efforts. Findings from 4 Harvard School of Public Health College Alcohol Study surveys: 1993-2001. Journal of American College Health 50(5), 203-217. https://doi. org/10.1080/07448480209595713

Wen, X., Kanny, D., Thompson, W. W., Okoro, C. A., Town, M., \& Balluz, L. S. (2012). Binge drinking intensity and health-related quality of life among US adult binge drinkers. Preventing Chronic Disease, 9. https://doi.org/10.5888/pcd9.110204

White, A. M. (2017). Commentary on Patrick and colleagues: Highintensity drinking among young adults in the United States: Prevalence, frequency, and developmental change. Alcoholism: Clinical and Experimental Research, 41(2), 270-274. https://doi. org/10.1111/acer.13306 